Portland State University

PDXScholar

Communication Faculty Publications and

Presentations

Communication

$11-1-2009$

\title{
Relevance and Simulation in Metaphor
}

L. David Ritchie

Portland State University, cgrd@pdx.edu

Follow this and additional works at: https://pdxscholar.library.pdx.edu/comm_fac

Part of the Communication Commons

Let us know how access to this document benefits you.

\section{Citation Details}

Published as: Ritchie, L. D. (2009). Relevance and simulation in metaphor. Metaphor and Symbol, 24(4), 249-262.

This Post-Print is brought to you for free and open access. It has been accepted for inclusion in Communication Faculty Publications and Presentations by an authorized administrator of PDXScholar. Please contact us if we can make this document more accessible: pdxscholar@pdx.edu. 


\title{
Relevance and Simulation in Metaphor
}

\author{
L. David Ritchie \\ Department of Communication \\ Portland State University \\ Portland, OR 97207 \\ cgrd@pdx.edu \\ (503) 725-3550
}

Metaphor and Symbol, 24, 249-262

David Ritchie is Professor of Communication at Portland State University in Portland

Oregon. In addition to other articles in Metaphor and Symbol, recent publications on cognitive theories of metaphor include Context and Connection in Metaphor Theory, Palgrave-MacMillan, 2006. 


\title{
Relevance and Simulation in Metaphor
}

\author{
Abstract \\ Recent writings have done much to develop and extend Relevance Theory as an \\ account of metaphors and other "loose" language use. However, it is argued in this essay \\ that Relevance Theory still leaves important gaps in its explanation and does not \\ adequately address the "circularity" issue that has been raised. It is proposed that \\ Perceptual Simulation Theory usefully extends Relevance Theory by providing a detailed \\ cognitive mechanism for the "broadening” and "narrowing” specified by Relevance \\ Theory . Extending Relevance Theory to include the cognitive mechanisms posited by \\ Perceptual Simulation Theory also extends the reach of Relevance theory and enhances \\ its ability to explain previously un-attended examples of metaphor, including \\ metaphorical stories, strings of interacting metaphors, and humorous and playful \\ distortions of metaphors.
}




\section{Relevance and Simulation in Metaphor}

\section{Introduction}

How do people make sense of metaphorical words and phrases? Are the emotional effects and sensory images associated with metaphors and other figurative language merely peripheral to the cognitive effects of processing these words and phrases, or do these effects and images contribute to their meaning?

Recent refinements and extensions of Relevance Theory have greatly expanded its ability to explain how metaphors are used and understood, how they achieve cognitive effects (Carston, 2002; Vega Moreno, 2007; Wilson \& Carston, 2006; Wilson and Sperber, 2004). In this essay I argue that the Relevance Theory account of metaphor still has some gaps and potential contradictions, and that the perceptual simulations approach to cognitive processing (Barsalou, 2007; 2008; Gibbs, 2006; Zwaan, 2008) can strengthen and broaden Relevance Theory’s account of metaphor use and provide a more complex and subtle account of contextual effects, an account that explicitly includes the emotions and images activated by metaphorical language. I will then show how these ideas can contribute to our understanding of metaphors in actual discourse.

In their recent writings, Wilson and Sperber (2004) have developed and refined the initial explanation of Relevance Theory (Sperber \& Wilson, 1996) to show how Relevance Theory can explain the comprehension of metaphors as well as other "loose" language use. Relevance is defined as the capacity of an input, such as an utterance or gesture, to yield positive cognitive effects, to alter the individual's representation of the world in a way and to an extent that justifies the effort required to process the input. Relevance Theory assumes that human cognition has evolved to maximize relevance and 
accordingly that every ostensive stimulus carries twin presumptions: (a) that it is sufficiently relevant to justify the effort required to process it, and (b) that it is the most relevant stimulus the communicator is able and willing to produce in the current situation. These assumptions lead to a comprehension procedure in which the audience follows a path of least effort that includes both broadening or enriching and narrowing the stimulus until either the resulting interpretation meets expectations of relevance or the attempt to accomplish relevance is abandoned.

Wilson and Sperber point out that virtually all language is to some extent "loose," in that most words are associated with categories that include many more properties than will ever be relevant to any particular communicative context, and that consequently all communication requires an interpretive process beyond mere decoding. In Wilson and Sperber's view, comprehension must always involve some narrowing (excluding properties that are irrelevant in the present context) and will usually also involve some broadening (extending the ordinary range of associated properties). Wilson and Carston (2006, pp. 409-10) provide commonplace examples of both processes. In "all politicians drink,” the ordinary reference of $d r i n k$ is narrowed to include only consumption of alcoholic beverages; in "buying a house is easy if you've got money," money is narrowed to include only large sums; in “it’s boiling hot today," boiling is broadened to include any exceptionally high temperature.

Relevance and Metaphor. Wilson and Sperber (2004) assert that metaphor does not require any special treatment, and that all forms of language use, including metaphor, rely on the same basic processes of inference, employing both broadening and narrowing in the search for optimal relevance. Carston (2002, p. 328) gives several examples of 
how broadening can explain the interpretation of metaphorical phrases, including "Here's my new flatmate” (referring to a newly acquired cat). Although ordinarily understood as a human being (who usually contributes to rent and other expenses), "flatmate" is also ordinarily understood as providing companionship, which a pet cat is also expected to do. Human being is a sub-category of living animal, which includes cats, along with other non-human animals that are known to provide companionship, so broadening FLATMATE $^{*}$ to include other members of the inclusive category, LIVING ANIMAL, seems at most odd rather than contradictory. A second example, “Jim’s bedroom is a rubbish dump," affords a similar analysis. Although rubbish dump includes attributes (large trucks backing up and emptying their contents) that do not apply to a bedroom, it also includes qualities such as physical disorder, unsightliness, and perhaps uncleanness that can literally apply to a bedroom, and thus provide a straightforward basis for broadening RUBBISH DUMP* to include other members of the inclusive category, DISORDERLY, UNSIGHTLY, AND UNCLEAN SPACES.

In each of these cases, the broadening process that renders the phrase relevant in its context invites multiple weak implicatures, including those based on the incongruity of the ad hoc category (Raskin, 1985; Raskin \& Attardo, 1994) and the resultant humor. It appears to be the potential for these weak implicatures that justify the use of the metaphorical phrase instead of a more literal alternative (e.g., companion or unsightly mess, respectively), although as Gibbs and Tendahl (2006) argue, the metaphorical versions do not necessarily require more processing efforts than a literal equivalent, and the contextual effects achieved are not necessarily proportional to the processing effort.

\footnotetext{
${ }^{1}$ Consistent with Wilson and Carston's usage I indicate categories in small capital letters and ad hoc categories in small capital letters followed by an asterisk.
} 
Previous work (Ritchie and Dyhouse, 2008) has shown that the humor and, in some cases, playfulness of metaphorical language may supply some of the cognitive effects, independently of any possible changes to the hearer's understanding of the topic.

Wilson and Carston (2006; see also Vega Moreno, 2007) discuss two other examples that pose slightly more difficulty. "Caroline is a princess" is spoken in reply to a question, “Will Caroline help with the packing?” According to Wilson and Carston, here princess is broadened to form an ad hoc concept PRINCESS*, that includes “spoiled, indulged, and self-centered” (and narrowed to exclude “person born to a royal family”). But this metaphor is ambiguous - “princess” is also widely used as an endearment, suggesting qualities like "person who behaves nobly; person who is adored." To disambiguate these alternative ad hoc concepts, the hearer might rely on extralinguistic cues including vocal inflections as well as background knowledge about Caroline and her relationship with the speaker. This example also illustrates the fact that the cognitive effects from processing a phrase may include not only effects on the ostensible topic (packing for a move) but also effects on the hearer's understanding about the social and relational context, e.g. about Caroline's personality and the speaker's feelings about Caroline. The humorous remarks identifying a new pet as a flatmate and Jim’s bedroom as a rubbish dump also seem likely to achieve cognitive effects on relational and social contexts: In all three cases, the relational and social contextual effects may be more important than the effects on the more immediate conversational topic.

Circularity in the RT account of metaphor interpretation. Another example provided by Wilson and Carston (2006) and discussed at length by Carston and others, 
"Robert is a bulldozer," may present problems not presented by any of these other examples, as Carston (2002) concedes. ${ }^{2}$ If Robert happens to be an offensive lineman (in American Football) who is especially good at clearing a path for the ball-carrier, or a celebrity's body-guard, who is good at clearing a path through a crowded street, then extending the concept of “obstacles” to embrace "opposing tacklers” or "other pedestrians" might be accomplished through a kind of "broadening" of semantic reference; "obstacles" might easily be broadened to include people who impede the actual physical movement of the ball-carrier or celebrity. By the same token, bulldozer is easily broadened to include a person who is especially effective at removing these (human) obstacles, and the opposing tacklers or obstructing pedestrians, like boulders on a construction site, are literally pushed out of the way (and may, in the extreme, literally be run over and suffer actual physical injury). In this context, the Relevance Theory account of metaphors can be applied without difficulty to "Robert is a bulldozer."

However, as the "bulldozer" example is presented by Wilson and Carston (2006), Robert is the speaker's boss (or colleague) who "pushes his own ideas energetically" and "runs over" other people’s objections (thereby conveying a sense of disrespect and obstinacy and "hurting” listeners' feelings). But an objection to a proposed plan of action that someone raises in a staff meeting is an "obstacle," and insisting on a particular idea is "pushing" that idea only after a metaphorical mapping has already been accomplished. Similarly, preventing further discussion of the objection constitutes "removing the obstacle" only in a sense that is also already metaphorical (Ritchie, 2003b, p. 50).

\footnotetext{
${ }^{2}$ Wilson and Carston report finding only three metaphorical uses of "bulldozer" in the British National Corpus, one of which referred to a football player, and two of which referred to a nickname for Jacques Chirac (footnote 17, page 428).
} 
Wilson and Carston acknowledge what they call the "metaphor within a metaphor” problem (2006, p. 416) and Ritchie (2003b, p. 50) calls the “circularity” problem: How is it that the category, BULLDOZER, a heavy piece of construction equipment, can come to include qualities associated with thinking, emotional, social entities? In effect, in order to construct an ad hoc category, BULLDOZER*, that includes emotion and social behavior, either BULLDOZER or other concepts associated with it (such as PUSH AROUND and RUN OVER) must already have been given a metaphorical interpretation. The Relevance Theory explanation implicitly assumes that metaphorical interpretation has already happened (Ritchie, 2003a).

Wilson and Carston suggest two possible solutions to the "circularity” or “metaphor within metaphor” problem (2006, p. 426). One possible solution is that "these metaphorically extended senses have arisen through broadening of the basic physical senses... to create superordinate concepts... which are not purely psychological but have both physical and psychological instances.” How this can be accomplished, and how a single superordinate concept can apply to both physical and psychological experience, are left unexplained. The second solution proposed by Wilson and Carston is that words and phrases like hard and cold, push around and remove obstacles are polysemous, having distinct and independent physical and psychological senses. Wilson and Carston acknowledge that these senses "might have arisen, in the history of the language or the individual, via narrowing of such broader superordinate senses” (p. 426-7) but they do not provide any mechanism by which such an extension to such a broad and inclusive concept, from which distinct meanings could be narrowed, might have come about in the 
first place. One "explanation” pushes the question down a level and the other pushes it back in history - neither really explains the phenomenon.

Carston (2002, pp. 354-356) discusses two other possible solutions to the circularity problem. The first possibility refers to "the general human capacity for making analogies,” including the potential for mapping or aligning structures across domains. However, as Carston admits, it is not easy to see exactly how this process might account for BULLDOZER*. The second possibility, only briefly discussed by Carston but developed at length by Gibbs and Tendahl (2006) is based on the claim of Conceptual Metaphor Theory (Lakoff \& Johnson, 1980) that humans have a number of pre-existing conceptual metaphors, based on correlations in direct experience, which form the basis for our more abstract concepts and are expressed in various verbal metaphors. Relevant conceptual metaphors identified in the Conceptual Metaphor literature include PSYCHOLOGICAL FORCE IS PHYSICAL FORCE and PEOPLE ARE MACHINES. Either of these could account for the BULLDOZER* example; INSISTING IS PHYSICAL FORCE in combination with something like UNPREDICTABLE IS PHYSICALLY UNCONSTRAINED could account for another of Carston’s (2002) otherwise troublesome examples, “loose cannon.”

In this same passage, Carston acknowledges the "striking imagistic quality" of many metaphors: "Even in the utterly banal bulldozer case, people report having a mental image of a bulldozer," perhaps merged with an image of Robert "so that we see Robert as a bulldozer” (p. 356; emphasis in original). Carston also acknowledges “other non-propositional effects” that are sometimes achieved by poetic metaphors, including “qualitative states of mind,” such as sensations and feelings. In the next section I will 
argue that these "non-propositional effects" are not peripheral but central to the understanding of many metaphors, and that they are alone capable of fully resolving the circularity or "metaphor within a metaphor" problem, in some instances but not always in combination with the conceptual metaphor account proposed by Gibbs and Tendahl.

As Carston notes, Conceptual Metaphor Theory has come under heavy criticism during the past decade or so (see for example Glucksberg \& McGlone, 1999; Keysar et al., 2000; Murphy, 1996; Vervaeke \& Kennedy, 1996). As Gibbs and Tendahl note, there is a rapidly accumulating body of evidence (for a detailed review see Gibbs, 2006) in support of the claim that conceptual metaphors such as ANGER IS PRESSURIZED FLUID IN A CONTAINER and EMOTIONAL INTIMACY IS WARMTH reflect underlying mappings across domains. Gibbs cites extensive experimental results confirming, for example, that phrases such as "blew his stack" or "a heated argument," in which anger and other strong emotions are expressed in terms of physical heat and pressurized fluid or gas activates schemas related to PRESSURIZED FLUID IN A CONTAINER (see also Gibbs, 1994; Zwaan, 2004) Similarly, Zhong and Leonardelli (2008) report that an induced experience of social rejection (i.e., "a chilly reception”) increases the probability that a research participant will judge the physical temperature of the laboratory as uncomfortably cold, supporting the idea that the emotional and sensory experiences are connected at a fundamental cognitive level.

\section{Simulations}

Gibbs (2006) has proposed an account of language processing that builds on the fundamental insights of Conceptual Metaphor Theory, proposing that metaphors activate schemas associated with the metaphor vehicle, leading listeners to experience simulations 
of the perceptual experience. Thus, "blew his stack," "boiling mad," or "a heated argument" partially activates much the same neural pathways that would be activated by seeing a steam boiler explode or by feeling a stream of very hot liquid or gas. "Robert is a bulldozer" would partially activate a schema of a bulldozer, blended with Robert's features, pushing its way through the conference room, pushing people aside or running over the top of them.

Barsalou’s (1999; 2007; 2008) Language and Situated Simulation (LASS) theory extends and provides a more general theoretical basis for Gibbs’s model (Ritchie, 2006; 2008). Barsalou acknowledges that language is sometimes processed in terms of connections to other words and phrases, consistent with Kintsch (1998) and Landauer \& Dumais (1997). However, Barsalou claims that deeper processing (and more complex reasoning) is accomplished by activating partial or complete simulations of perceptions that are associated with the word or phrase and with the related schemas (see also Zwaan, 2004; 2008). These simulated perceptions include proprioceptive and introspective awareness of the body's internal state and thought processes as well as exteroceptive perceptions of the external environment. Thus, "blew his stack" or "a chilly reception" might activate a complete "hot fluid in a container" or "immersion in cold water" schema, as proposed by Gibbs, or it might lead the hearer to experience simulations of only a few related perceptions, perhaps of a loud noise, violent activity, and the emotion of anger in the first instance, and a sensation of cold and the emotion of rejection in the second instance. In a situation of very low listener involvement, these phrases might activate only a connection to one or two related words (e.g., anger and not welcome, respectively). 
Ritchie (2008b) argues that a phrase (metaphorical or not) may activate a complete (conceptual metaphor-based) schema, as proposed by Gibbs (2006), a few connected words (consistent with Kintsch, 1998), or a limited set of partial simulations associated with the schema (as per Barsalou, 2007). If a listener is not processing the language deeply, perhaps because of a low level of personal involvement, a stock metaphor like "princess" may be processed only at a surface level, by activating links to associated words and phrases such as "royalty,” "spoiled,” self-centered," "person who behaves nobly,” or “person who is adored.” However, if the context calls for deeper processing (for example if the speaker develops the metaphor in an extended story or if listener involvement is high), listeners may actually experience emotional simulations of resentment or adoration, audial simulations of loud temper tantrums or soft, melodic speech, perhaps accompanied by a visual simulation of a lovely young woman wearing a tiara and expensive gown.

According to this view, Bulldozer would be expected to activate an array of perceptual simulations including simulations of actual earth-moving equipment in operation that may include visual images, sound, the visceral sensations of low-frequency earth vibrations, and emotions such as fear, respect, and awe (the vivid imagery mentioned by Carston, 2002). Crucially for “Robert is a bulldozer,” introspective simulations are also activated related to the power of bulldozers, their relatively slow movement, the difficulty of stopping them, and their ability to crush anything that might be in front of their treads (the “other non-propositional effects” mentioned by Carston, 2002, p. 356). In addition to these simulations that are directly connected with bulldozer, introspective simulations and semantic connections may be recalled from previous 
discourse in which bulldozers figured, either literally (as in discussion of a construction project) or metaphorically (as in previous encounters with related metaphors) as part of an extended and socially-constructed BULLDOZER* schema. All of these are available to be activated, connected inferentially with Robert and his recently-described (or anticipated) behavior, and contribute to cognitive effects.

Although I concur with Carston (2002) and other critics that the case for the existence of an extensive array of stable conceptual metaphors is still unsettled, the fundamental insight underlying Conceptual Metaphor Theory suggests a way in which perceptual (emotional and introspective) simulations associated with domineering and aggressive people may have become associated with BULLDOZER* in the first place. Lakoff and Johnson (1980) argue that abstract concepts may become closely linked with “embodied" experience (perceptions and actions) through repeated association, beginning in early childhood. Pertinent to the BULLDOZER* example, from early childhood we have co-occurring experiences of negation and frustration associated with physical force, motion, and impediments to physical motion. Thus we have "conceptual metaphors," embodied as neural links between physical and cognitive / emotional experiences in a field of meaning (Ritchie, 2003b; 2006) that includes, among others, something like “DOMINANCE IS PHYSICAL FORCE”, “INSISTING IS PUSHING,” "DISSENT IS PHYSICAL OBSTRUCTION.”

\section{Metaphors in actual discourse.}

Thus far the discussion has focused almost exclusively on metaphors invented to illustrate a certain point. In this section I will look at several metaphors that appear in actual discourse, some taken from data I and my students and colleagues have collected 
and some taken from public sources. Many of the metaphors come in clusters, and as Cameron (2007) argues, this clustering of metaphors is itself an important part of the cognitive context.

“In so deep you can't get out”: A conversation about urban homelessness. In a conversation among a group of college students and other young adults about homelessness (Ritchie, 2009; in press), one participant observed that homeless people eventually "get to that point where they just wander the streets and talk to themselves." Discussing the barriers facing poor people in seeking steady employment, participants noted that "you have to have somewhere to start from"; they also criticized the harshness of the capitalist system because "you really have nowhere to start from.” Describing a typical sequence of events in the life of a homeless person, one participant observes that “it goes from.. drugs to uh... you know, like, mental illness” and another participant says you get so deep into it you can’t you can’t get back out.

[eh heh]

You're on the streets talking to yourself

[yep!]

yah know.. starts with something small and builds up. Throughout this conversation, on the streets was sometimes used literally, sometimes metonymically, sometimes metaphorically, and sometimes, as seems to be the case here, both literally and metaphorically - just as journey of reconciliation in Cameron (2007) can be understood as simultaneously literal and metaphorical. "Starts with something small and builds up" exemplifies another common phenomenon, the combination of a metaphor based on JOURNEY (starts with) with a metaphor based on CONSTRUCTION 
(builds up). "Builds up" is also used to describe other phenomena such as the way waves increase in height as they approach shore and the increasing thickness of solid substance in processes such as sedimentation; "start small and build up" is often used to describe the process of starting a business enterprise. Various hearers may have processed the metaphor according to any of these common uses, or they may have experienced only general perceptual simulations weakly associated with several of them.

"Get to that point," "someplace to start from," "get in deep," and "start small and build up" are all standard idioms, and may well be processed strictly in terms of their semantic connections (Kintsch, 2008). “Get so deep into it you can’t you can’t get back out" illustrates a fairly common phenomenon, a metaphor within a metaphor. "Deep in debt” can refer to indebtedness, including college loans but "get in deep" can also refer to gambling debts; either metaphor may activate simulations of emotions and cognitions associated with excessive indebtedness. It also seems likely that this phrase may activate perceptual simulations associated with drowning, as in a deep river or perhaps quicksand, which also underlie the debt metaphor. As with "builds up," any or all of these perceptual simulations may contribute to the contextual effects.

It is unlikely that any of these expressions require much lexical broadening or that they activate full conceptual schemas, but in combination with each other and with the many other JOURNEY metaphors as well as literal phrases like "wander the streets," they seem to have activated perceptual simulations associated with movement, particularly aimless movement, and with entrapment and resultant inability to move. Both the semantic links and the activated simulations contribute to the contextual effects, including a reinforcement of the tension between free movement, aimless movement, and 
entrapped inability to move; this three-way tension emerged repeatedly during the eightyminute conversation, in a variety of metaphors, stories, and humorous comments (Ritchie, in press).

We're in an unstable foundation: Scientists talk about communication. The second sample comes from a focus-group conversation among a group of scientists (all engaged in doing basic research in a government-funded lab) who were asked to discuss their role as scientists and the importance of communicating about their work with members of the public (Ritchie \& Schell, 2009). A few minutes into the conversation, one participant commented, in reference to the need to be perpetually concerned about funding, “there’s no more ivory tower.” About a minute later, another participant referred back to this comment:

Participant 4: Jack said something, one way of of capturing part of that, ah, change of role is ah, no more ivory tower. It's probably, we're, we're not there now.. it's probably not too far in the future. Participant 2: I've never really seen the ivory tower. (Laughter) Participant 4: You haven't. They never did let you in did they? Participant5: Is that what you dream about, in the night, Jim? ivory tower you just go to sleep and the first thing you get is the seven million dollar grant from.. to do whatever you want.. from the MacArthur Foundation.. and you go up into the ivory tower. What the, open pit, unstable wall Participant1: Ya the unstable.

Participant4: Ya, instead of the ivory tower, we're in an unstable foundation. 
"Ivory tower" is a familiar idiom for academic research and may not have been, initially, processed beyond the semantic level. When Jack said “"'there’s no more ivory tower,” all of the listeners are certain to have recognized the idiom and accessed the associated “knowledge for its own sake” schema, consistent with Carston’s polysemy account as well as with Barsalou's claims about simulation of mental states (including the regret a basic researcher feels about the need to be perpetually concerned about securing funding). The JOURNEY metaphors, "not there now" and "not too far in the future" are also stock metaphors that would require little processing and can readily be explained either in terms of polysemy or in terms of links to other semantic knowledge. When Participant 2 combined these two stock metaphors, it may have led some participants to process the metaphors more fully, but even this combination could conceivably be processed with little broadening (Carston) or activation of perceptual simulations (Gibbs, Barsalou).

"I’ve never seen the ivory tower" was clearly intended as a humorous comment about the speaker's own situation, shared with the other scientist-participants. Its humor requires activating both the PURE SCIENCE and the STRUCTURE schemas associated with the "ivory tower" idiom along with the VISUAL PERCEPTION schema underlying the idiomatic use of see as a synonym for experience: The humor lies in the incongruity of treating "ivory tower" simultaneously as an idiomatic expression of an unattainable ideal and an actual structure that occupies space and can be seen - or not. To appreciate the mock-pathos and irony of the comment, listeners need to activate both simulations of the visual perception of a tall white structure and the introspective perception of an ideal situation. 
Participant 4 built on this juxtaposition of frames with his ironically teasing rejoinder, “They never did let you in did they?” Here, visual, introspective, and emotional simulations associated with "ivory tower" as a structure, an exclusive citadel to which entry is excluded and the introspective and emotional simulations associated with the idiomatic sense of "ivory tower" as a sort of academic sinecure were simultaneously activated and contrasted with the actual conditions in which Jim works.

Participant 5 extended this juxtaposition of frames by asking "Is that what you dream about, in the night, Jim?” then filled in the ideal situation schema by describing the hope of waking up to a huge no-strings grant from the MacArthur Foundation, and combined it with the structure schema: “and you go up into the ivory tower.” Finally, he began the process of extracting a very different entailment by describing this remote and idealized structure in terms of instability and decay: "What the, open pit, unstable wall." Two other participants then joined the narration, culminating in a summary of the situation facing the scientists as a group: “instead of the ivory tower, we're in an unstable foundation.”

This exchange began with a humorous complaint about the need to be continually concerned about funding, followed by a teasing jab at the complaining speaker, then was developed into a metaphorical commentary on the situation facing these scientists, which may have been intended as a commentary on the situation of science in general: "we're in an unstable foundation," combining the two distinct meanings of foundation, having to do with A PHYSICAL STRUCTURE and A CHARITABLE INSTITUTION in a bit of apparently extemporaneous word-play. As Carston notes (2002, quoted in the preceding), metaphorical language has the ability to activate powerful imagery: In this example, the 
visual imagery activated by "ivory tower," along with the other perceptual simulations, including simulations of emotions (pathos, yearning, frustration, etc.) does not seem to be incidental or peripheral to the cognitive and interactive processes; rather, these simulations appear to have played a central function both in constructing and reshaping the metaphor and in understanding it. It is difficult to say at what point the participants in the conversation began processing the metaphorical language more deeply, and began experiencing the associated schemas and perceptions fully, and each of them may have reached that point at a slightly different time. From the sequence of metaphorical utterances and responses, it does seem certain that they were all experiencing richly detailed perceptual simulations by the end of the passage.

This passage also illustrates a couple of other interesting aspects of metaphor use in actual discourse. First, there is a decidedly playful aspect to the metaphor use (see Ritchie \& Dyhouse, 2008), as the participants collaboratively activate, distort, and transform the metaphor- and yet this language play does not interfere with the "task at hand,” which is to come to some common understanding of the role of scientists in communicating with non-scientists (Ritchie \& Schell, 2009). Second, the metaphors appear as part of an extended idealized story, a story that is itself metaphorical, in that it expresses their shared story as scientists. The homelessness conversation consisted almost entirely of a sequence of stories, some drawn from personal experience, some second-hand or drawn from media, and some - like the "ivory tower" story - generic. Other stories in the homelessness conversation were implied by metaphors such as "you get so deep into it you can’t you can't get back out" and "starts with something small and builds up.” 
In sum, metaphors may be combined with stories in several distinct ways. Metaphors often imply stories (“““we're in an unstable foundation”), they often appear within stories, and conversely, stories often have a metaphorical cast to them, as illustrated by Jim's imputed dream ${ }^{3}$. The general neglect of the narrative aspects of metaphor use in metaphor theory and research seems surprising, but it can probably be explained by the reliance on short made-up examples, in which narrative elements are less noticeable and may be absent altogether.

Schank and Abelson (1995) claim that stories are the primary medium of memory: How we tell something is how we remember it. Schank and Abelson do not address the implications of this theory for collective story-telling as a source of collective memory but their overall account is very consistent with Sperber's (1996) ideas about the formation of ‘cultural representations' through repetition and refining of a common story. Gibbs and Tendahl (2006) comment on the paucity of evidence that metaphor use increases memory retention; if there is an effect, it may be that it will be found in the narratives activated by or associated with the metaphors rather than in the more static perceptual simulations and schemas activated by the metaphors.

Barack Obama - “The fire next time.” Barack Obama’s campaign for the U.S. Presidency relied critically on his ability to keep issues of race in the background. However, at a crucial point in the campaign he was forced to confront the race question when a potentially damaging controversy erupted over a series of comments, widely

\footnotetext{
3 Another example of a story that serves as a metaphor appears in Tony Blair's (2005) speech to the Labour Party annual conference at Gateshead, analyzed at length in Ritchie (2008b): all of a sudden there you are, the British people, thinking: you're not listening and I think: you're not hearing me. And before you know it you raise your voice. And I raise mine. Some of you throw a bit of crockery. And now you, the British people, have to sit down and decide whether you want the relationship to continue
} 
regarded as unpatriotic, made by his personal friend and spiritual adviser, the Reverend Jeremiah Wright. In his speech, “A more perfect union” (Obama, 2008), Obama made liberal use of both metaphors and stories, many of them thematically related to both sides of the American story, a story that was underscored by his reference to his wife, Michelle, who "carries within her the blood of slaves and slaveowners." "Blood" is a stock idiom for both family descent and racial descent, and as such links readily to a network of related terms, including (in this context) terms related to miscegenation and racial purity. Blood also activates strong perceptions of violence and wounds, and “within her" activates a sense of extreme intimacy, a sense also realized in the practice, common in many traditional cultures, of mixing blood from superficial wounds to become "blood brothers." 4

Obama made strong use of several other conceptual metaphors or metaphor groups, notably including FIRE and JOURNEY. When Obama characterized Reverend Wright's language as 'incendiary’ and referred to the ensuing controversy as a 'firestorm,' hearers may actually have experienced Wright's language as fire, based on the underlying conceptual metaphor, PASSION IS HEAT, consistent with Conceptual Metaphor Theory. This is a common and familiar conceptual metaphor, expressed in poetry and music as well as everyday usage (e.g., 'That burns me up'). According to simulation theory these metaphors may only have partially activated neural circuits that would be fully activated by actual perceptions of intense fire. Either way, by repeating the metaphors based on FIRE and HEAT, Obama reinforced the underlying conceptual metaphor, intensifying and probably extending the experienced simulations. For some of

\footnotetext{
${ }^{4}$ Until less than fifty years ago it was illegal in many states in the U.S. not only to marry a person of a different race but also to give blood transfusions across racial boundaries.
} 
his listeners, this phrasing may also have evoked other connections with fire (both semantic and perceptual), including the Biblical allusion used as a title by AfricanAmerican writer James Baldwin, 'The fire next time,' as well as the race riots of the late 1960s that spawned the slogan, 'burn, baby, burn.' Obama used up a closely related HEAT metaphor in the phrase 'seared into my genetic makeup,' a phrase that also has the potential to evoke emotionally intense connections (at least among his African-American listeners) with the practice of branding slaves with hot irons. It is important to note that these metaphors, like many of the stories Obama told, refer to background knowledge that is almost certainly very different for various groups within his audience, particularly for White Americans, African Americans, and immigrants who came to the country well after the passage of the civil rights laws of the 1960s.

Obama used repetition and transformation of common metaphors extensively, including metaphors based on JOURNEY. At the beginning of his 'campaign,' Obama set the task to 'continue the long march of those who came before us.' The use of this metaphor potentially links the campaign to the literal 'freedom marches' of the Civil Rights movement as well as to the more conventional 'march of progress' metaphor. Asserting the need for unity, Obama observes that 'we may not have come from the same place, ${ }^{5}$ but we all want to move in the same direction.' Referring to the temptation to ignore 'the issues that have surfaced... that we've never really worked through,' Obama

\footnotetext{
5 "we may not have come from the same place" can be interpreted literally as well as metaphorically Obama comes from Indonesia and Hawaii as well as Chicago, his mother and grandmother came from Kansas, and his father came from Kenya. His later reference to relatives "scattered across three continents" reinforces a literal reading in parallel to the metaphorical reading.
} 
asserts that 'if we walk away now... simply retreat into our respective corners ${ }^{6}$, we will never be able to come together...'

It seems likely that the cognitive effects from processing the perceptual simulations associated with Obama’s metaphorical language include not only completing listeners' understanding of his ideas about the general topic, race, and the immediate topic of the speech, Reverend Wright's intemperate language; these cognitive effects also include potential changes in listeners’ feelings and ideas about the social and political structure of U.S. society, and about our shared history. Appearing in a major campaign speech by the first African-American President, these metaphors and the schemas and simulations they activate, including the stories, must also inevitably affect the context for future discourse on these and related topics. To encompass the full meaning of these metaphors and of the sequence of stories the comprised the bulk of Obama's speech, the notion of context needs to be broadened well beyond the context of preceding sentences to embrace the entire extended conversation about race. This approach may also help to link the analysis of specific texts, discourse in a micro-social sense, with the analysis of ideological modes of speaking and writing, discourse in a macro-social or cultural sense (e.g., Goatly, 2007; Koller, 2004).

Notable in Obama's speech is the use of both metaphors and stories to activate strong perceptual and emotional simulations alongside historical schemas. The language of BLOOD and FIRE activates multiple episodes from the history of race relations in the United States; the many references to journeys, both real and metaphorical, activate memories (for older listeners) and stories learned at second-hand (for younger listeners)

\footnotetext{
${ }^{6}$ This is clearly a BOXING metaphor as well as a MOTION and SEPARATION metaphor; as such it activates simulations of suspended strife and watchful wariness.
} 
from the civil rights movement as well as other, earlier journeys that figure in U.S. history. The powerful effect of the speech can be best understood by attending to the activation of a series of powerful simulations including the visual and visceral simulations activated by metaphors like "seared into my genetic makeup" as well as the more complex simulations of "carries within her the blood of slaves and slave-owners."

Obama addressed an audience that included people with very different experiences of exactly the same events, and these differences must be considered in any analysis of the effects of his language, either at the individual or the societal level. He acknowledged and addressed these differences repeatedly throughout the speech, using metaphors (like the JOURNEY metaphor) that are more likely to be experienced in similar ways by all members of the audience and by telling parallel stories in a way that emphasized their underlying similarity. For example Obama explained the anger of African Americans like Reverend Wright by referring to the lingering effects of discriminatory laws and employment practices in a series of powerful mini-stories about blacks who "scratched and clawed their way to get a piece of the American Dream but were ultimately defeated." He then acknowledged in a series of parallel mini-stories that "a similar anger exists within segments of the white community, among working-class whites who have "worked hard all their lives, many times only to see their jobs shipped overseas or their pension dumped."

Summary. In each of the samples discussed, metaphors are used and understood in a complex discursive context that includes mutual knowledge about the topic, along with mutual knowledge about the relationships among participants and, in the case of Obama's speech, mutual knowledge about the cultural, political, and historical 
background on which Obama drew for his metaphors and stories. The metaphors, stories, and (in the scientist's discussion) humor and teasing activated schemas and perceptual simulations that were relevant and had potentially strong contextual effects not only with respect to the shared understanding about the immediate topic but also with respect to the shared understanding about the relationships among the participants. The effects of the metaphors and stories also include changes to the immediate cognitive context in which subsequent communication would take place. This is apparent at the micro-scale of a few minutes in the scientist's conversation, where subsequent remarks built on the simulations activated by previous remarks. ${ }^{7}$ In the case of Obama's speech, it is apparent both at the micro-scale of the speech itself and at a more macro-scale, potentially extending throughout much of his presidency and beyond.

Some of the metaphors analyzed in this section can be readily traced to underlying conceptual metaphors, but even in these cases understanding the cognitive effects requires consideration of the perceptual simulations and, in some cases, of the schemas and narratives they activated - and of the probability that many of them activated very different simulations, schemas, and narratives for different listeners. The relevance model provides a powerful tool for understanding how these words and phrases are understood and connected with previously-activated knowledge and beliefs within the mutual cognitive environment. However, it requires the processes of perceptual simulation or something along very similar lines to explain the nature of the stipulated cognitive effects, and to explain how the same metaphor or narrative, heard in the same overall context, can affect different hearers in very different ways.

\footnotetext{
${ }^{7}$ According to the facilitator, these context-altering effects continued throughout the day-long meeting within which the scientists' conversation took place, as these participants carried the jocular themes into other conversations and meetings throughout the day (Schell, personal communication).
} 


\section{Discussion.}

I concur with Gibbs and Tendahl’s (2006) assessment that Relevance Theory, supplemented by the basic insights of Conceptual Metaphors, provides the potential to explain the cognitive processes of metaphor use and understanding, but in the foregoing I have argued that perceptual simulations are a necessary part of the account, not as an incidental by-product but as a central mechanism for the accomplishment of contextual effects. I have also suggested that the idea of contextual effects may usefully be expanded to include effects on hearers' understanding of the broader relational and cultural context and, incorporating a time dimension, on the context within which subsequent utterances will be processed. Finally, I have shown that a consideration of metaphors in the context of actual discourse must include stories, both the stories that are implied by many metaphors and the stories and story-sequences within which they often occur.

I also concur with Wilson and Sperber (2004) that metaphors do not necessarily require unique comprehension processes. Consistent with Wilson and Sperber's claims, in a simulation-based account a vivid word or phrase need not be metaphorical to accomplish extended weak implicatures (weakly activate multiple perceptual simulations), and there is no necessary reason why metaphors would require any different form of processing than other language. Whether the word or phrase is used literally or metaphorically, it will activate salient parts of one or more schemas, with the associated perceptual simulations. Those that are less relevant will remain inactivated or be suppressed and those that are more relevant will be enhanced, may receive further elaboration, and will be connected with the activated elements of the topic schema in a 
way that accomplishes a range of cognitive effects. The only difference between the processing of literal and metaphorical language is that in metaphorical language, most of the perceptual simulations and semantic links associated with the usual or primary meaning of the word or phrase will be suppressed through narrowing.

Including simulations provides a way to bring the emotional effect of communication, including the simple pleasure people get from word play and other types of non-informative communicative interaction, into the model rather than treating it as peripheral and secondary or unimportant. Given the amount of time people seem to spend on apparently non-informative communication, this seems important for developing any truly comprehensive account of language use and communication generally. 


\section{References.}

Barsalou, L. W. (2008). Grounding symbolic operations in the brain’s modal systems. Chapter 1, pp. 9-42 in Semin, Gün R., and Smith, Eliot R. (Eds.). Embodied grounding: Social, cognitive, affective, and neuroscientific approaches. Cambridge, UK: Cambridge University Press.

Barsalou, L. W. (2007). Grounded cognition. Annual Review of Psychology, 59, 617-45.

Barsalou, L. (1999). Perceptual symbol systems. Behavioral and Brain Sciences, 22, 577-609.

Blair, T. (2005). A fight we have to win. A speech to Labour’s Spring Conference. Gateshead, England: Sage Centre. http://politics.guardian.co.uk/speeches/story/0,,1412459,00.html, accessed 05/01/2007.

Cameron, L. J. (2007). Patterns of metaphor use in reconciliation talk. Discourse and Society, 18, 197-222.

Carston, R. (2002). Thoughts and utterances: The pragmatics of explicit communication. Oxford, England: Blackwell.

Gibbs, R. W. Jr. (2006). Metaphor interpretation as embodied simulation. Mind and Language, 21, 434-458.

Gibbs, R. W. Jr. (1994). The poetics of mind: Figurative thought, language, and understanding. Cambridge, England: Cambridge University Press.

Gibbs, R. W., Jr., and Tendahl, M. (2006). Cognitive effort and effects in metaphor comprehension: Relevance theory and psycholinguistics. Mind \& Language, 21, 379-403. 
Glucksberg, S. and McGlone, M. (1999). When love is not a journey: What metaphors mean. Journal of Pragmatics, 31, 1541-58.

Goatly, A. (2007). Washing the brain - Metaphor and hidden ideology. Amsterdam: John Benjamins.

Keysar, B., Shen, Y., Glucksberg, S., and Horton, W. (2000). Conventional language: How metaphorical is it? Journal of Memory and Language, 43, 576-93.

Kintsch, W. (1998). Comprehension: A paradigm for cognition. Cambridge, England: Cambridge University Press.

Kintsch, W. (2008).. How the mind computes the meaning of metaphor: A simulation based on LSA. In R. W. Gibbs, Jr., Ed., The Cambridge handbook of metaphor and thought (pp. 129-142). Cambridge, UK: Cambridge University Press.

Koller, V. (2004). Metaphor and gender in business media discourse: A critical cognitive study. Basingstoke, UK: Palgrave Macmillan Ltd.

Lakoff, G., and Johnson, M. (1980). Metaphors we live by. Chicago, IL: University of Chicago Press.

Landauer, T. K., and Dumais, S. T. (1997). A solution to Plato’s problem: The latent semantic analysis theory of acquisition induction, and representation of knowledge. Psychological Review, 104, 211-240.

Murphy, G. (1996). On metaphorical representation. Cognition, 60, 173-204.

Obama, B. (2008). A More Perfect Union. A speech delivered on March 18, 2008 in the Constitution Center, Philadelphia, PA. http://www.msnbc.msn.com/id/23690567/, most recently accessed 06/19/09.

Raskin, V. (1985). Semantic mechanisms of humor. Boston, MA: D. Reidel. 
Raskin, V., and Attardo, S. (1994). Non-literalness and non-bona-fide in language: An approach to formal and computational treatments of humor. Pragmatics \& Cognition, 2(1), 31-69.

Ritchie, L. D. (in press). "You're lying to Jesus!” Humor and play in a discussion about homelessness. To appear in Humor.

Ritchie, L. D. (2009). Metaphor, narrative, and social reality in a conversation about homelessness. A paper presented to the International Communication Association at its annual conference in Chicago, IL.

Ritchie, L. D. (2008a). X IS A JOURNEY: Embodied Simulation in Metaphor Interpretation. Metaphor and Symbol 23, 174 - 199.

Ritchie, L. D. (2008b). Gateshead Revisited: Perceptual Simulators and Fields of Meaning in the Analysis of Metaphors. Metaphor and Symbol 23, 24 - 49.

Ritchie, L. D. (2006). Context and Connection in Metaphor. Basingstoke, UK: Palgrave Macmillan Ltd.

Ritchie, L. D. (2003a). Categories and Similarities: A Note on Circularity. Metaphor and Symbol, 18, 49-53.

Ritchie, L. D. (2003b). “ARGUMENT IS WAR” - Or is it a game of chess? Multiple meanings in the analysis of implicit metaphors. Metaphor and Symbol, 18, 125146.

Ritchie, L. D., and Dyhouse, V. (2008). Hair of the Frog and other Empty Metaphors: The Play Element in Figurative Language. Metaphor and Symbol, 23, 85107. 
Ritchie, L. D. and Schell, C. (2009). “The ivory tower” on an "unstable foundation”: Playful Language, Humor, and Metaphor in the Negotiation of Scientists’ Identities. Metaphor and Symbol, 24, 90 - 104.

Schank, R. C. and Abelson, R. P. (1995). Knowledge and memory: The real story. In Robert S. Wyer (ed.), Knowledge and memory: The real story. Advances in Social Cognition, Vol. VIII. Hillsdale, NJ: Lawrence Erlbaum Associates, 1-86.

Sperber, D. (1996). Explaining culture: A naturalistic approach. London: Blackwell.

Sperber, D., and Wilson, D. (1996). Relevance: Communication and cognition. Cambridge, MA: Harvard University Press.

Vega Moreno, R. E. (2007). Creativity and convention: The pragmatics of everyday figurative speech. Amsterdam: John Benjamins.

Vervaeke, J. and Kennedy, J. M. (1996). Metaphors in language and thought: Falsification and multiple meanings. Metaphor and Symbolic Activity, 11, 273-284. Wilson, D., and Carston, R. (2006). Metaphor, relevance and the 'emergent property’ issue. Mind \& Language, 21, 404-433.

Wilson, D. and Sperber, D. (2004). Relevance Theory. Chapter 27, pp.607-632 in Horn, Laurence R. and Ward, Gregory, eds., The handbook of pragmatics. Oxford, UK: Blackwell Publishing.

Zhong, C.-B., and Leonardelli, G. J. (2008). Cold and lonely: Does social exclusion literally feel cold? Psychological Science, 19, 838-842.

Zwaan, R. A. (2008). Time in language, situation models, and mental simulations. Language Learning, 58, 13-26. 
Zwaan, R. A. (2004). The immersed experiencer: Toward an embodied theory of language comprehension. In B. H. Ros (Ed.), The Psychology of Learning and Motivation, Vol. 44 (pp. 35-62). New York, NY: Academic Press. 